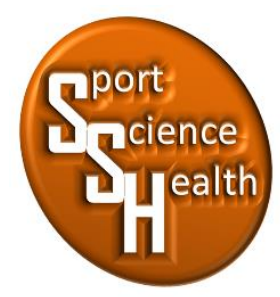

ISSN 2715-3886

\title{
Survei Kemampuan Kondisi Fisik Peserta Kegiatan Ekstrakurikuler Sepakbola SMP
}

\author{
Fani Alfaridhi ${ }^{1 *}$, Siti Nurrochmah ${ }^{2}$ \\ 1,2Jurusan Pendidikan Jasmani, Kesehatan dan Rekreasi, Fakultas IImu Keolahragaan, \\ Universitas Negeri Malang, Jalan Semarang No 5, Malang, Jawa Timur, 65145, Indonesia \\ *Penulis koresponden: fanialfarifhi@gmail.com, 085933108918
}

Artikel diterima: 9 Januari 2020; direvisi: 15 Februari 2021; disetujui: 22 Februari 2021

\begin{abstract}
The purpose of this study was to determine and assess the ability of the physical condition of the participants in the football extracurricular activities at SMP Negeri 15 Malang. This study used a quantitative descriptive survey design. The subjects of this study were 30 participants in extracurricular football activities at SMP Negeri 15 Malang. The data was collected using a test form measurement technique, namely a test of the ability of the physical condition in the form of a test of motion agility, movement speed, flexibility of motion and leg muscle explosive power. The results of data analysis on the participants of the extracurricular football activities at SMP Negeri 15 Malang included (1) shuttle run agility 43, 3\% medium category (2) running speed $50 \mathrm{~m} 5.33 \%$ medium category (3) body flexibility sit and reach $43.3 \%$ medium category and (4) leg muscle explosive power standing board jump 33.3\% moderate category. Based on the results of the study, it was concluded that the participants of extracurricular football activities at SMP Negeri 15 Malang, the physical condition of the agility element was included in the "medium" category, the element of running speed was included in the "medium" category, the flexibility element was included in the "medium" category, and the element of leg muscle explosive power was included in the "category" medium ".
\end{abstract}

Keyword: physical condition, extracurricular, football

Abstrak: Tujuan penelitian ini adalah untuk mengetahui dan mengkaji kemampuan kondisi fisik peserta kegiatan ekstrakurikuler sepakbola SMP Negeri 15 Malang. Penelitian ini menggunakan rancangan survei bentuk deskriptif kuantitatif. Subyek penelitian ini berjumlah 30 orang peserta kegiatan ekstrakurikuler sepakbola SMP Negeri 15 Malang. Pengumpulan data menggunakan teknik pengukuran bentuk tes yaitu tes kemampuan kondisi fisik berupa tes kelincahan gerak, kecepatan gerak, kelentukan gerak dan daya ledak otot tungkai.Hasil analisis data pada peserta kegiatan ekstrakurikuler sepakbola SMP Negeri 15 Malang antara lain (1) kelincahan shuttle run 43,3\% kategori sedang (2) kecepatan lari 50 m 5,33\% kategori sedang (3) kelentukan tubuh sit and reach 43,3\% kategori sedang dan (4) daya ledak otot tungkai standing board jump33,3\% kategori sedang. Berdasarkan hasil penelitian disimpulkan bahwa pada peserta kegiatan ekstrakurikuler sepakbola SMP Negeri 15 Malang kemampuan kondisi fisik unsur kelincahantermasuk kategori "sedang", unsur kecepatan lari termasuk kategori "sedang", unsur kelentukan termasuk kategori "sedang", dan unsur daya ledak otot tungkai termasuk kategori "sedang".

Kata kunci: kondisi fisik, ekstrakurikuler, sepakbola

\section{PENDAHULUAN}

Layanan kegiatan ekstrakurikuler untuk penguasaan keterampilan siswa maka sekolah wajib memberikan layanan sesuai dengan bakat dan minat siswa, misalnya dapat berupa layanan ekstrakurikuler pramuka, tari, 
bolabasket, futsal dan sepakbola. Kegiatan ektrakurikuler merupakan kegiatan yang dilakukan dalam mengembangkan aspek-aspek tertentu dari apa yang ditemukan pada kurikulum yang sedang dijalankan, termasuk yang berhubungan dengan bagaimana penerapan sesungguhnya dari ilmu pengetahuan yang dipelajari oleh peserta didik sesuai dengan tuntutan kebutuhan hidup mereka maupun lingkungan sekitarnya (Adiningtyas, Tomi, \& Yudasmara, 2020; Kurniadi, Wahyudi, \& Heynoek, 2019).

Panduan mengenai ekstrakurikuler terdapat dalam Lampiran Standar Isi berdasar Peraturan Mentri Pendidikan Nasional (Permendiknas No.22 Tahun 2006). Dalam Lampiran Standar Isi Permendiknas No.22 Tahun 2006 berisikan 3 komponen yakni komponen mata pelajaran, muatan lokal dan pengembangan diri, dalam komponen pengembangan diri. Bertolak dari landasan yuridis tersebut lebih jelas bahwa kegiatan ekstrakurikuler merupakan komponen pengembangan diri yang bertujuan untuk membina jasmani dan daya kreasi siswa di sekolah.Di antara beberapa kegiatan ekstrakurikuler tersebut, sepakbola merupakan kegiatan yang paling diminati oleh para siswa di setiap sekolah, karena permainan sepakbola sangat digemari oleh masyarakat pada saat ini mulai dari kaum hawa, kaum pria dan anak-anak, senada dengan penelitian Noperto (2013) yang menunjukkan bahwa sepakbola adalah permainan yang paling banyak diminati dan merupakan olahraga yang terpopuler bagi remaja saat ini. Selain menjadi olahraga yang paling diminati, permainan ini sangat mudah untuk dilakukan dan juga menyenangkan sedangkan penelitian yang dilakukan Alesi, Bianco, Luppina, Palma, \& Pepi (2016) menunjukkan bahwa bermain sepakbola dapat meningkatkan fungsi keterampilan dalam tubuh dan membuat psikis seseorang menjadi gembira. Selain itu, masyarakat juga sering mengisi waktu luang dengan bermain sepakbola.Hal tersebut juga dapat dibuktikan dari banyaknya club-club sepakbola yang ada di daerah, baik di dalam ataupun luar negeri, sejalan dengan ini pertumbuhan dan perkembangan sepakbola juga didukung dengan adanya pertandingan-pertandingan di tingkat daerah maupun tingkat nasioanal bahkan internasioal.

Sepakbola adalah permainan dengan cara menendang sebuah bola yang diperebutkan oleh para pemain dari dua kesebelasan yang berbeda dengan bermaksud memasukkan bola ke gawang lawan dan mempertahankan gawang sendiri jangan sampai kemasukan bola (Irianto, 2010:3). Permainan sepakbola dimainkan oleh 22 orang pemain yang dibagi menjadi 2 tim, kedua tim saling menyerang ke daerah pertahanan tim lawan dengan maksud dan tujuan mencetak gol sebanyak-banyaknya guna memenangkan pertandingan. Sepakbola bertujuan untuk berlomba-lomba memasukkan bola ke gawang lawan dengan sebanyakbanyaknya sehingga tim yang paling banyak memasukkan bola akan menjadi juaranya. Untuk saat ini, pembinaan sepakbola sangat beraneka ragam mulai dari berdirinya akademi sepakbola, sekolah sepakbola, dan juga diklat sepakbola yang cukup menjanjikan. Diklat sepakbola tersebut tentunya harus memiliki manajemen dan pembinaan yang standar agar menciptakan atlet sepakbola yang potensial (Smith et al., 2016; Turner \& Stewart, 2014).

Sebagaimana yang dinyatakan oleh para ahli bahwa Persiapan fisik merupakan suatu hal yang penting dalam masa persiapan sebuah tim untuk mencapai prestasi yang optimal. Melalui latihan fisik, kondisi pemain yang kurang baik akan meningkat setelah melakukan latihan fisik yang terprogram dengan baik, hasil dari latihan fisik tersebut dapat dilihat dari meningkatnya penampilan seorang pemain yang akhirnya berdampak positif pada penampilan tim (Mora-Gonzalez et al., 2019; Rhyu \& Cho, 2014; Voss et al., 2016).

Oleh sebab itu di dalam latihan olahraga terdapat latihan kondisi fisik untuk keterampilan gerak dasar yang teratur dan sebaiknya dimulai sejak usia dini (Reilly, Dick, McNeill, \& Tremblay, 2014; Sharif et al., 2016; Tremblay et al., 2014; Wijtzes et al., 2016). Begitu juga dengan sepakbola, memerlukan kemampuan kondisi fisik yang dikarenakan luas lapangan sepakbola yang cukup memakan energi pemain serta membutuhkan kerjasama tim (Smith et al., 2016; Turner \& Stewart, 2014; Verburgh, Scherder, Van Lange, \& Oosterlaan, 2014). Kondisi fisik dapat dilihat dari kemampuan fisik (physical abilities) atlet, seperti kesegaran jasmani. Priambodo (2013), berpendapat bahwa komponen kesegaran jasmani yang berhubungan dengan kesehatan ialah sebagai berikut: (a) daya tahan jantung dan paru, (b) kekuatan dan daya tahan otot, (c) kelentukan, (d) komposisi tubuh. Komponen kesegaran jasmani terdiri atas: (a) daya tahan kardiorespirasi, (b) daya tahan otot, (c) kekuatan otot, (d) kelenturan, (e) komposisi tubuh, (f) kecepatan gerak, (g) kelincahan, (h) keseimbangan, dan (i) kecepatan reaksi.

Kemampuan fisik memerlukan adanya suatu latihan unsur-unsur kondisi fisik antara lain, daya tahan (endurance), kekuatan (strenght), kecepatan (speed), daya ledak (power), kelentukan (fleksibelity), kelincahan (agility), Koordinasi (coordination), dan keseimbangan (balance) (Dwijayanto, 2017:2). Berdasarkan hal di atas 
berarti sepakbola merupakan permainan yang membutuhkan unsur-unsur tersebut khususnya daya tahan (Endurance), kecepatan (speed) dan kelincahan (agility), sehingga dalam dunia pendidikan, para peserta ekstrakurikuler sepakbola di sekolah-sekolah membutuhkan beberapa komponenlatihan guna mendapatkan kondisi fisik yang baik, kegiatan ekstrakurikulerlah yang dijadikan sebagai sarana atau wadah pembinaan dan peningkatan kondisi fisik terhadap kesegaran jasmani pemain sepakbola untuk mendapatkan kondisi fisik yang baik tersebut.

Berdasarkan pengamatan yang dilakukan peneliti terhadap kegiatan ekstrakurikuler sepakbola di sekolah tersebut, peneliti mendapat kesimpulan bahwa pelatih belum pernah melakukan pengukuran dalam bentuk tes terhadap komponen-komponen kondisi fisik yang menunjang kegiatan ekstrakurikuler sepakbola, karena di sekolah tersebut hanya menekankan pada teknik dasar permainan sepakbola dan kurang memperhatikan kondisi fisik peserta dalam kegiatan ekstrakurikuler tersebut.

Hasil penelitian yang dilakukan Utomo (2012), diperoleh profil kondisi fisik pemain futsal Porprov di Karisidenan Surakarta tahun 2012. Penelitian ini dilakukan dengan teknik pengukuran kondisi fisik yang disesuaikan dengan cabang sepakbola yaitu meliputi: (1) tes lari 60 meter, (2) tes shuttle run $6 \times 10$ meter, (3) tes loncat tegak (vertical jump), (4) tes kekuatan otot tungkai, (5) tes lari multi tahap (multistage test). Dari temuan studi pendahuluan tersebut serta hasil pengamatan peneliti dalam kegiatan ekstrakurikuler di SMP Negeri 15 Malang berarti penting dilakukan tes untuk mengetahui perkembangan kondisi fisik para peserta kegiatan ekstrakurikuler sepakbola SMP Negeri 15 Malang. Untuk mengetahui perkembangan kondisi fisik maka perlu dilakukan kajian berupa penelitian terkait kondisi fisik atau perkembangan komponen-komponen kondisi fisik dalam bentuk tes melalui penelitian terhadap komponen kondisi fisik.

Bertolak padauraian masalah serta studi pendahuluan yang berpijak pada hasil studi yang menunjukkan hasil sebagaimana yang telah dipaparkan, maka permasalahan tersebut menarik untuk diteliti. Oleh karena yang melatar belakangi masalah ini adalah tentang keadaan kondisi fisik, utamanya pada tingkat perkembangan kondisi fisik yang dimiliki oleh peserta kegiatan ekstrakurikuler sepakbola di SMP Negeri 15 Malang, maka peneliti mengkaji masalah tersebut melalui penelitian yang berjudul "Survei Kemampuan Kondisi Fisik Peserta Ekstrakurikuler Sepakbola SMP Negeri 15 Malang".

\section{METODE}

Penelitian ini menggunakan rancangan survei bentuk deskriptif kuantitatif. Ditinjau dari tujuan penelitian, jenis penelitian ini termasuk jenis penelitian deskriptif. Variabel yang diteliti berupa kemampuan kondisi fisik yang meliputi kemampuan (a) kelincahan gerak, (b) kecepatan gerak, (c) kelentukan gerak, dan (d) daya ledak otot tungkai peserta kegiatan ekstrakurikuler sepakbola SMP Negeri 15 Malang.Subjek dalam penelitian ini adalah peserta kegiatan ekstrakurikuler sepakbola SMP Negeri 15 Malang berjumlah 30 orang.Instrumen penelitian yang digunakan dalam penelitian ini adalah instrumen tes dan non tes. Tes digunakan untuk mengukur kemampuan kelincahan gerak shuttle run, kecepatan gerak lari $50 \mathrm{~m}$, kelentukan gerak sit and reach dan daya ledak otot tungkai standing board jump. Sedangkan non tes dilakukan dalam bentuk wawancara kepada pelatih ekstrakurikuler sepakbola SMP Negeri 15 Malang.Pengumpulan data dalam penelitian ini menggunakan teknik pengukuran bentuk tes yaitu tes kemampuan kondisi fisik berupa tes kelincahan gerak shuttle run, kecepatan gerak lari $50 \mathrm{~m}$, kelentukan gerak sit and reach, dan daya ledak otot tungkai standing board jump.

\section{Teknik Analisis Data}

Berdasarkan pada tujuan penelitian dan jenis data yang diperoleh dari tes kelincahan, kecepatan, kelentukan, dan daya ledak otot tungkai berupa data rasio, maka teknik analisis data yang digunakan untuk mengungkap tentang keadaan kemampuan kondisi fisik peserta kegiatan ekstrakurikuler sepakbola SMP Negeri 15 Malang adalah statistika deskriptif kuantitatif.Teknik analisis statistika deskriptif kuantitatif yang digunakan berupa mean, median, modus,standar deviasi sampel, variansi sampel dan koefisien variansi (KV).

\section{HASIL}

Proses pengambilan data kondisi fisik peserta kegiatan ekstrakurikuler sepakbola SMP Negeri 15 Malang menggunakan sit and reach test, lari $50 \mathrm{~m}$, sit and reach, dan standing board jump. Dari data yang diperoleh 
dianalisis menggunakan statistika deskriptif bentuk tabel yang meliputi sekor minimal, skor maksimal, ratarata (mean), nilai tengah (median), dan nilai yang sering muncul (modus). Pada tabel 4.1 berikut ini akan menyajikan hasil tes kondisi fisik peserta kegiatan ekrtrakurikuler sepakbola SMP Negeri 15 Malang.

Tabel 1. Deskripsi Data Hasil Tes Kemampuan Kondisi Fisik Peserta Kegiatan Ekstrakurikuler Sepakbola SMP Negeri 15 Malang

\begin{tabular}{cccccc}
\hline \multirow{2}{*}{$\begin{array}{c}\text { Nama } \\
\text { Lembaga }\end{array}$} & $\begin{array}{c}\text { Ukuran } \\
\text { Tendensi } \\
\text { Sentral }\end{array}$ & $\begin{array}{c}\text { Shuttle Run } \\
\text { (detik) }\end{array}$ & $\begin{array}{c}\text { Lari 50 m } \\
\text { (detik) }\end{array}$ & $\begin{array}{c}\text { Sit and Reach } \\
\text { (cm) }\end{array}$ & $\begin{array}{c}\text { Standing } \\
\text { Board Jump } \\
\text { (cm) }\end{array}$ \\
\hline \multirow{2}{*}{ SMP } & Min & 12,42 & 8,09 & 1,3 & 1,13 \\
Negeri 15 & Max & 15,3 & 11,38 & 20,6 & 1,92 \\
Malang & 13,6077 & 9,7173 & 11,18667 & 1,495333 \\
& Median & 13,45 & 9,75 & 11,45 & 1,45 \\
& Modus & 13,36 & 8,38 & 12,8 & 1,45 \\
\hline
\end{tabular}

Berdasarkan data deskriptif peserta kegiatan ekstrakurikuler sepakbola SMP Negeri 15 Malang yang masingmasing berjumlah 30 peserta pada bentuk tes kelincahan gerak (shuttle run) diperoleh skor minimum 12,42 detik, skor maksimum 15,3 detik, rata-rata skor setiap tes 13,6077 detik, nilai tengah skor setiap tes 13,45 detik, dan nilai yang sering muncul setiap tes 13,36. Berdasarkan data deskriptif peserta kegiatan ekstrakurikuler sepakbola SMP Negeri 15 Malang yang masing-masing berjumlah 30 peserta pada bentuk tes kecepatan gerak lari 50 m diperoleh skor minimum 8,09 detik, skor maksimum 11,38 detik, rata-rata skor setiap tes 9,7173 detik, nilai tengah skor setiap tes 9,75 detik, dan nilai yang sering muncul setiap tes 8,38 detik.

Berdasarkan data deskriptif peserta kegiatan ekstrakurikuler sepakbola SMP Negeri 15 Malang yang masingmasing berjumlah 30 peserta pada bentuk tes kelentukan gerak (sit and reach) diperoleh skor minimum 1,3 $\mathrm{cm}$, skor maksimum 20,6 cm, rata-rata skor setiap tes $11,18667 \mathrm{~cm}$, nilai tengah skor setiap tes $11,45 \mathrm{~cm}$, dan nilai yang sering muncul setiap tes $12,8 \mathrm{~cm}$. Berdasarkan data deskriptif peserta kegiatan ekstrakurikuler sepakbola SMP Negeri 15 Malang yang masing-masing berjumlah 30 peserta pada bentuk tes daya ledak otot tungkai (standing board jump) diperoleh skor minimum $1,13 \mathrm{~cm}$, skor maksimum 1,92 cm, rata-rata skor setiap tes $1,495333 \mathrm{~cm}$, nilai tengah skor setiap tes $1,45 \mathrm{~cm}$, dan nilai yang sering muncul setiap tes $1,45 \mathrm{~cm}$. Penyajian hasil analisis deskriptif bentuk tabel menyajikan bentuk tes sit and reach test, lari $50 \mathrm{~m}$, sit and reach, dan standing board jump pada peserta kegiatan ekstrakurikuler sepakbola SMP Negeri 15 Malang disajikan dalam bentuk tabel berikut ini.

Tabel 2 Deskripsi Hasil Analisis Data Tes Kemampuan Kondisi Fisik Peserta Kegiatan Ektrakurikuler Sepakbola SMP Negeri 15 Malang

\begin{tabular}{cccccc}
\hline \multirow{2}{*}{ No } & \multirow{2}{*}{ Jenis Tes } & \multicolumn{4}{c}{ Macam-nacam Tes Statistika } \\
\cline { 3 - 6 } & & Mean & SD & Varian & KV (\%) \\
\hline 1 & Shuttle Run & 13,6077 detik & 0,6502 detik & 0,423 detik & 4,7 \\
2 & Lari $50 \mathrm{~m}$ & 9,7173 detik & 0,8109 detik & 0,6576 detik & 8,3 \\
3 & Sit and Reach & $11,18667 \mathrm{~cm}$ & $4,970307 \mathrm{~cm}$ & $24,70395 \mathrm{~cm}$ & 44,4 \\
4 & Standing Board & $1,495333 \mathrm{~cm}$ & $0,228348 \mathrm{~cm}$ & $0,052143 \mathrm{~cm}$ & 15 \\
& & & & \\
& Jump & & & & \\
\hline
\end{tabular}

Berdasarkan hasil analisis statistika deskriptif yang meliputi standar deviasi, varian dan koefisien variansi maka diantara kelima butir tes tersebut, bahwa hasil analisis koefisien variansi (KV) pada Tabel 4.2 tersebut, sit and reach test memiliki $\mathrm{KV}=44,4 \%$ lebih besar dibandingkan dengan tes shuttle run, lari $50 \mathrm{~m}$, dan standing board jump. Berarti data hasil sit and reach test menunjukkan lebih beragam (datanya yang paling menyebar atau antar individu tidak memiliki kesamaan hasil tes) dibandingkan dengan data hasil shuttle run, lari $50 \mathrm{~m}$ dan standing board jump.

Pada shuttle run test memiliki KV 4,7\% berarti hasil shuttle run test menunjukkan lebih concentred (memusat) dengan kata lain menunjukkan lebih banyak skor-skor yang mendekati sama pada tiap testi dibandingkan dengan data tes lari $50 \mathrm{~m}$, sit and reach dan standing board jump. Untuk tes lari $50 \mathrm{~m}$ memiliki KV 8,3\% berarti 
hasil tes lari 50 m menunjukkan lebih concentred (memusat) dengan kata lain menunjukkan lebih banyak skorskor yang mendekati sama pada tiap testi dibandingkan dengan data shuttle run test, sit and reach dan standing board jump. Untuk standing board jump test memiliki KV $15 \%$ berarti hasil standing board jump test menunjukkan lebih concentred (memusat) dengan kata lain menunjukkan lebih banyak skor-skor yang mendekati sama pada tiap testi dibandingkan dengan data shuttle run test, tes lari $50 \mathrm{~m}$ dan sit and reach.

Dengan demikian keempat butir tes hasil shuttle run test, lari 50 m,dan standing board jump test menunjukkan mendekati kesamaan skor antar testi dibandingkan dengan hasil sit and reach test. Hasil sita and reach test skor tiap testi tidak banyak memiliki skor yang mendekati sama, dengan kata lain antar individu hasil tesnya beragam (paling menyebar).

Pada tahap berikutnya data hasil dari unsur kondisi fisik kelincahan gerak, kecepatan gerak, kelentukan gerak dan daya ledak otot tungkai dalam bentuk shuttle run test, lari $50 \mathrm{~m}$, sit and reach test dan standing board jump test dibandingkan dengan norma khusus yang disesuaikan. Di bawah ini disajikan tabel norma hasil dari unsur-unsur kondisi fisik kelincahan gerak, kecepatan gerak, kelentukan gerak, dan daya ledak otot tungkai dalam bentuk shuttle run test, tes lari $50 \mathrm{~m}$, sit and reach test, dan stand board jump test.Berikut hasil tes untuk mengukur kelincahan gerak, kecepatan gerak, kelentukan gerak, dan daya ledak otot tungkai sebagai bentuk nilai norma untuk mengukur kondisi fisik peserta kegiatan ekstrakurikuler sepakbola SMP Negeri 15 Malang.

Tujuan tes ini adalah untuk mengetahui kelincahan gerak dalam waktu yang dicapai dari lari bolak balik $4 \times 5$ $\mathrm{m}$ dalam satuan detik.

Tabel 3 Klasifikasi Hasil Tes Shuttle Run pada Peserta Kegiatan Ekstrakurikuler Sepakbola SMP Negeri 15 Malang

\begin{tabular}{ccccc}
\hline Rentang Norma & Prestasi (detik) & Frekuensi & Presentase & Norma \\
\hline$\leq \bar{X}-1,5$ SD Ke bawah & $\leq 12,63$ & 1 & $3,33 \%$ & Baik Sekali \\
$\bar{X}-1,5$ SD $<\bar{X}-0,5$ SD & $12,63-13,28$ & 8 & $26,6 \%$ & Baik \\
$\bar{X}-0,5$ SD $<\bar{X}+0,5$ SD & $13,28-13,93$ & 13 & $43,3 \%$ & Sedang \\
$\bar{X}+0,5$ SD $<\bar{X}+1,5$ SD & $13,93-14,58$ & 5 & $16,6 \%$ & Kurang \\
$\bar{X}+1,5$ SD Ke atas & $\geq 14,58$ & 3 & $10 \%$ & Kurang Sekali \\
Jumlah & & 30 & $100 \%$ & \\
\hline
\end{tabular}

Berdasarkan data di atas dapat dinyatakan bahwa hasil dari unsur kondisi fisik kelincahan gerak dalam bentuk shuttle run test pada peserta kegiatan ekstrakurikuler sepakbola SMP Negeri 15 Malang yang berjumlah 30 peserta dapat dideskripsikan hasil shuttle run test untuk norma baik sekali $3,33 \%$, norma baik $26,6 \%$, norma sedang $43,3 \%$, norma kurang $16,6 \%$, dan norma kurang sekali $10 \%$, jadi untuk hasil shuttle run test tergolong dalam klasifikasi sedang.

Hasil analisis deskriptif tes kondisi fisik kelincahan gerak dalam bentuk tes shuttle run pada peserta kegiatan ekstrakurikuler sepakbola SMP Negeri 15 Malang selengkapnya disajikan dengan grafik yang berdasarkan hasil dari norma tersebut. 


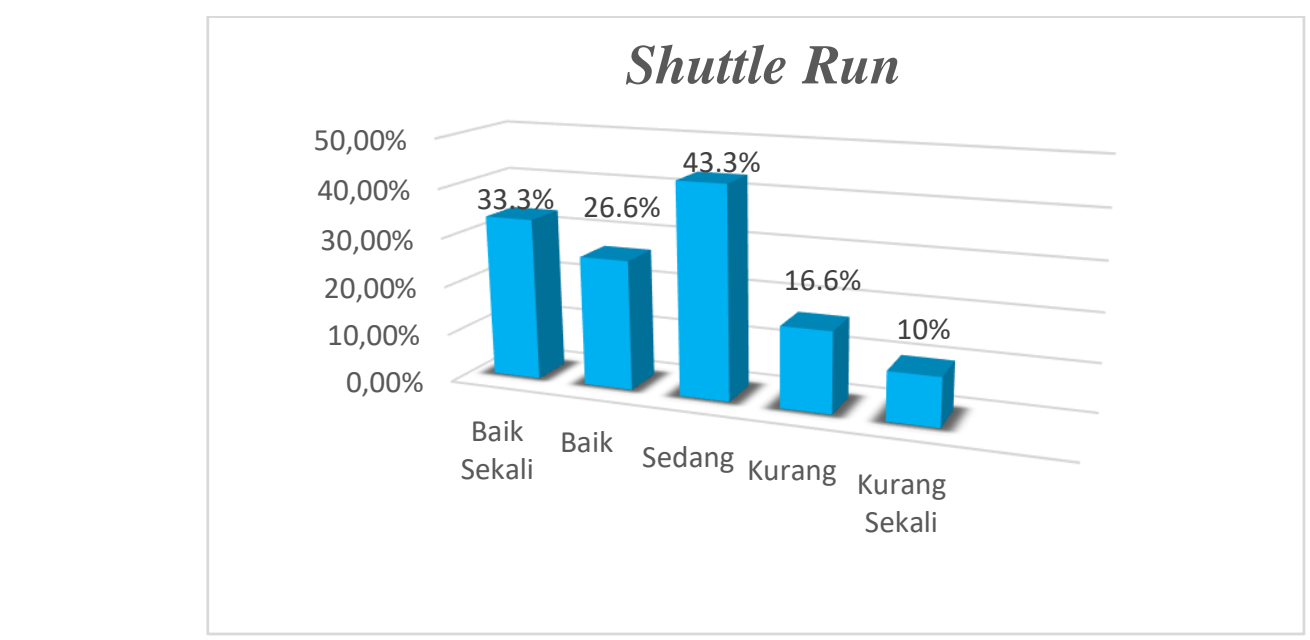

Gambar 1 Diagram Hasil Tes Kelincahan Gerak (Shuttle Run) Peserta Kegiatan Ekstrakurikuler Sepakbola SMP Negeri 15 Malang

Berdasarkan data hasil penelitian yang berkaitan dengan variabel tes kelincahan gerak (shuttle run) pada peserta kegiatan ekstrakurikuler sepakbola SMP Negeri 15 Malang yang berjumlah 30 peserta telah memiliki nilai baik sekali $33,3 \%$, nilai baik $26,6 \%$, nilai sedang $43,3 \%$, nilai kurang $16,6 \%$, dan nilai kurang sekali $10 \%$.

Tujuan tes ini adalah untuk mengetahui kecepatan gerak dalam waktu yang dicapai kecepatan berlari $50 \mathrm{~m}$ dalam satuan detik.

Tabel 4 Klasifikasi Hasil Tes Lari 50 mpada Peserta Kegiatan Ekstrakurikuler Sepakbola SMP Negeri 15 Malang

\begin{tabular}{ccccc}
\hline Rentang Norma & $\begin{array}{c}\text { Prestasi } \\
\text { (detik) }\end{array}$ & Frekuensi & Presentase & Norma \\
\hline$\leq \bar{X}-1,5$ SD Ke bawah & $\leq 8,50$ & 3 & $10 \%$ & Baik Sekali \\
$\bar{X}-1,5$ SD $<\bar{X}-0,5$ SD & $8,50-9,31$ & 4 & $13,3 \%$ & Baik \\
$\bar{X}-0,5$ SD $<\bar{X}+0,5$ SD & $9,31-10,12$ & 16 & 53,3 & Sedang \\
$\bar{X}+0,5$ SD $<\bar{X}+1,5$ & $10,12-10,93$ & 5 & $16,6 \%$ & Kurang \\
SD & & & & \\
$\bar{X}+1,5$ SD Ke atas & $\geq 10,93$ & 2 & $6,66 \%$ & Kurang Sekali \\
Jumlah & & 30 & $100 \%$ & \\
\hline
\end{tabular}

Berdasarkan data di atas dapat dinyatakan bahwa hasil dari unsur kondisi fisik kecepatan gerak dalam bentuk tes lari 50 mpada peserta kegiatan ekstrakurikuler sepakbola SMP Negeri 15 Malang yang berjumlah 30 peserta dapat dideskripsikan hasil shuttle run test untuk norma baik sekali $10 \%$, norma baik $13,3 \%$, norma sedang $53,3 \%$, norma kurang $16,6 \%$, dan norma kurang sekali $6,66 \%$, jadi untuk hasil tes lari 50 mtergolong dalam klasifikasi sedang.

Hasil analisis deskriptif tes kondisi fisik kecepatan gerak dalam bentuk tes lari 50 mpada peserta kegiatan ekstrakurikuler sepakbola SMP Negeri 15 Malang selengkapnya disajikan dengan grafik yang berdasarkan hasil dari norma tersebut. 


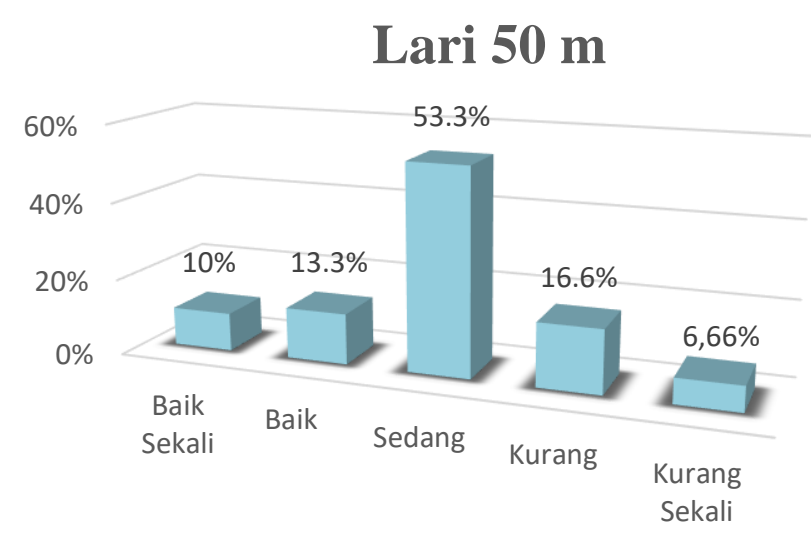

Gambar 2 Diagram Hasil Tes Kecepatan Gerak Lari 50 m Peserta Kegiatan Ekstrakurikuler Sepakbola SMP Negeri 15 Malang

Berdasarkan data hasil penelitian yang berkaitan dengan variabel tes kecepatan gerak lari $50 \mathrm{~m}$ pada peserta kegiatan ekstrakurikuler sepakbola SMP Negeri 15 Malang yang berjumlah 30 peserta telah memiliki nilai baik sekali $10 \%$, nilai baik $13,3 \%$, nilai sedang $53,3 \%$, nilai kurang $16,6 \%$, dan nilai kurang sekali $6,66 \%$.

Tujuan tes ini adalah untuk mengetahui kelentukan gerak dalam waktu hasil yang dicapai dalam melakukan tes sit and reach dalam satuan hitung centimeter.

Tabel 5 Klasifikasi Hasil Tes Sit and Reach pada Peserta Kegiatan Ekstrakurikuler Sepakbola SMP Negeri 15 Malang

\begin{tabular}{ccccc}
\hline Rentang Norma & Prestasi (cm) & Frekuensi & Presentase & Norma \\
\hline $\bar{X}+1,5$ SD Ke atas & $\geq 18,64$ & 2 & $6,66 \%$ & Baik Sekali \\
$\bar{X}+0,5$ SD $<\bar{X}+1,5$ SD & $13,67-18,64$ & 6 & $20 \%$ & Baik \\
$\bar{X}-0,5$ SD $<\bar{X}+0,5$ SD & $8,70-13-67$ & 13 & $43,3 \%$ & Sedang \\
$\bar{X}-1,5$ SD $<\bar{X}-0,5$ SD & $3,73-8,70$ & 5 & $16,6 \%$ & Kurang \\
$\leq \bar{X}-1,5$ SD Ke bawah & $\leq 3,73$ & 3 & $10 \%$ & Kurang Sekali \\
Jumlah & & 30 & $100 \%$ & \\
\hline
\end{tabular}

Berdasarkan data di atas dapat dinyatakan bahwa hasil dari unsur kondisi fisik kelentukan gerak dalam bentuk sit and reach test pada peserta kegiatan ekstrakurikuler sepakbola SMP Negeri 15 Malang yang berjumlah 30 peserta dapat dideskripsikan hasil sit and reach test untuk norma baik sekali $6,66 \%$, norma baik $20 \%$, norma sedang $43,3 \%$, norma kurang $16,6 \%$, dan norma kurang sekali $10 \%$, jadi untuk hasil sit and reach test tergolong dalam klasifikasi norma sedang.

Hasil analisis deskriptif tes kondisi fisik kelentukan gerak dalam bentuk tes (sit and reach)pada peserta kegiatan ekstrakurikuler sepakbola SMP Negeri 15 Malang selengkapnya disajikan dengan grafik yang berdasarkan hasil dari norma tersebut.

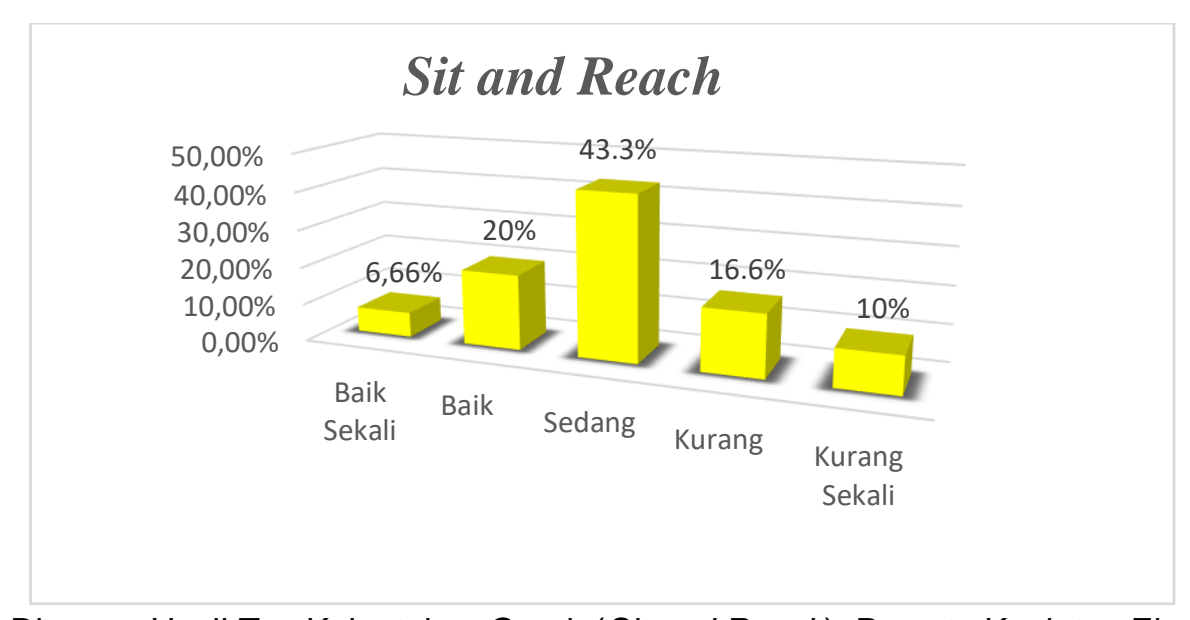

Gambar 3 Diagram Hasil Tes Kelentukan Gerak (Sit and Reach) Peserta Kegiatan Ekstrakurikuler Sepakbola SMP Negeri 15 Malang 
Berdasarkan data hasil penelitian yang berkaitan dengan variabel tes kelentukan gerak (sit and reach) pada peserta kegiatan ekstrakurikuler sepakbola SMP Negeri 15 Malang yang berjumlah 30 peserta telah memiliki nilai baik sekali $6,66 \%$, nilai baik $20 \%$, nilai sedang $43,3 \%$, nilai kurang $16,6 \%$, dan nilai kurang sekali $10 \%$.

Tujuan tes ini adalah untuk mengetahui daya ledak otot tungkai dalam hasil melompat tanpa awalan sejauh mungkin dengan kemampuan daya ledak semaksimal mungkin dengan satuan hitung centimeter.

Tabel 6 Klasifikasi Hasil Tes Standing Board Jump pada Peserta Kegiatan Ekstrakurikuler Sepakbola SMP Negeri 15 Malang

\begin{tabular}{ccccc}
\hline Rentang Norma & Prestasi (cm) & Frekuensi & Presentase & Norma \\
\hline $\bar{X}+1,5$ SD Ke atas & $\geq 1,84$ & 2 & $6,66 \%$ & Baik Sekali \\
$\bar{X}+0,5$ SD $<\bar{X}+1,5$ & $1,61-1,84$ & 7 & $23,3 \%$ & Baik \\
SD & & & & Sedang \\
$\bar{X}-0,5$ SD $<\bar{X}+0,5$ & $1,38-1,61$ & 10 & $33,3 \%$ & Kurang \\
SD & & 9 & $30 \%$ & Kurang Sekali \\
$\bar{X}-1,5$ SD $<\bar{X}-0,5$ & $1,15-1,38$ & & & \\
$\begin{array}{c}\text { SD } \\
\leq \bar{X}-1,5 \text { SD Ke } \\
\text { bawah } \\
\text { Jumlah }\end{array}$ & $\leq 1,15$ & 2 & $6,66 \%$ & \\
\hline
\end{tabular}

Berdasarkan data di atas dapat dinyatakan bahwa hasil dari unsur kondisi fisik daya ledak otot tungkai dalam bentuk standing board jump test pada peserta kegiatan ekstrakurikuler sepakbola SMP Negeri 15 Malang yang berjumlah 30 peserta dapat dideskripsikan hasil standing board jump test untuk norma baik sekali 6,66\%, norma baik $23,3 \%$, norma sedang $33,3 \%$, norma kurang $30 \%$, dan norma kurang sekali $6,66 \%$, jadi untuk hasil standing board jump test tergolong dalam klasifikasi sedang.

Hasil analisis deskriptif tes kondisi fisik daya ledak otot tungkai dalam bentuk tes (standing board jump)pada peserta kegiatan ekstrakurikuler sepakbola SMP Negeri 15 Malang selengkapnya disajikan dengan grafik yang berdasarkan hasil dari norma tersebut.

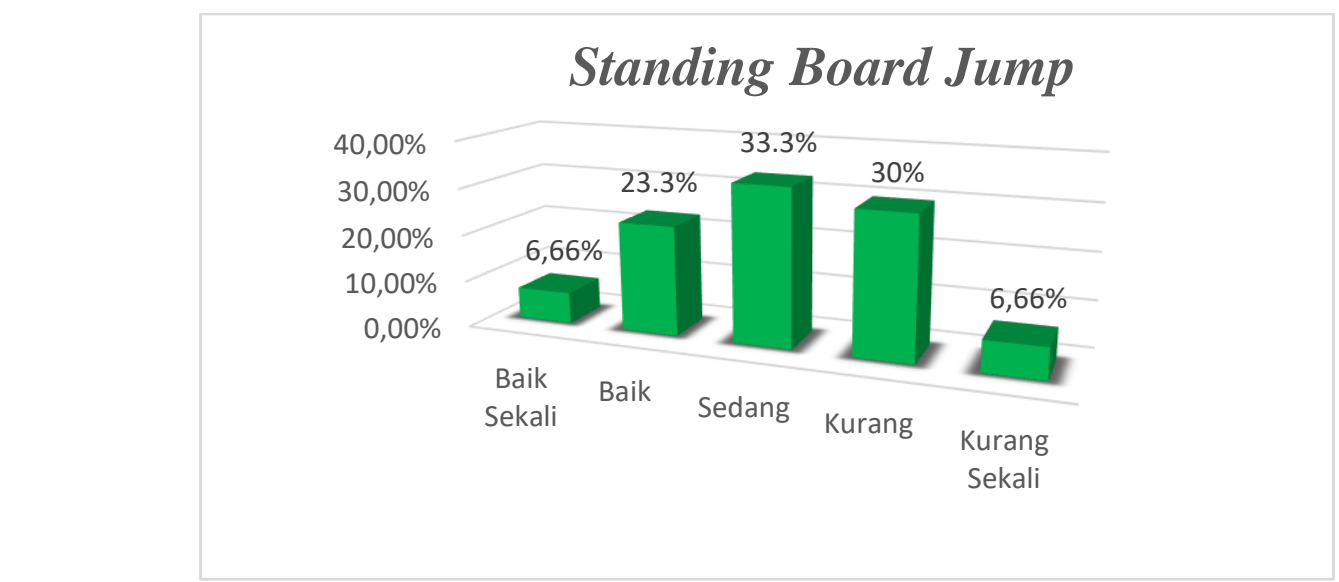

\section{Gambar 4 Diagram Hasil Tes Daya Ledak Otot Tungkai (Standing Board Jump) Peserta Kegiatan Ekstrakurikuler Sepakbola SMP Negeri 15 Malang}

Berdasarkan data hasil penelitian yang berkaitan dengan variabel tes daya ledak otot tungkai (standing board jump) pada peserta kegiatan ekstrakurikuler sepakbola SMP Negeri 15 Malang yang berjumlah 30 peserta telah memiliki nilai baik sekali $6,66 \%$, nilai baik $23,3 \%$, nilai sedang $33,3 \%$, nilai kurang $30 \%$, dan nilai kurang sekali $6,66 \%$.

\section{PEMBAHASAN}

Setelah dilakukan penghitungan dari masing-masing tes kemampuan kondisi fisik pada unsur kelincahan gerak, kecepatan gerak, kelentukan gerak dan daya tahan otot tungkai oleh peneliti, maka dapat diketahui 
bahwa hasil secara keseluruhan menjukkan bahwa kondisi fisik peserta kegiatan ekstrakurikuler sepakbola SMP Negeri 15 Malang berada pada kategori "sedang", yang didasarkan pada beberapa test (Shuttle Run, Lari 50 m, Sit and Reach, dan Standing Board Jump).

Kondisi di atas didapatkan sedemikian rupa dikarenakan di SMP Negeri 15 Malang hanya menekankan pada teknik dasar permainan sepak bola dan kurang memperhatikan kondisi fisik peserta dalam kegiatan ekstrakurikuler tersebut. Disamping dari hal di atas rutinitas latihan juga menjadi penentu kondisi fisik seorang, karena terbukti dengan adanya daftar hadir yang peneliti amati pada proses penelitian tidak penuh terisi, sehinngga ketidak hadiran peserta ekstrakurikuler dan yang juga tidak secara mandiri berlatih di luar ekstrakurikuler akan mendapatkan kondisi fisik yang kurang baik sebagaimana yang disampaikan oleh Hidayat, dkk. (2015:201-212), bahwa Kemampuan fisik memerlukan adanya suatu latihan. Salah satu komponen latihan yang diberikan untuk dapat meningkatkan kemampuan fisik seorang atlet yaitu dengan meningkatkan kelincahan dan lain sebagainya. Adapun pembahasan hasil dari pada penelitian yang lebih komprehensif akan dijelaskan sebagai berikut.

\section{Kondisi Fisik Kelincahan Gerak}

Kemampuan kondisi fisik pada unsur kelincahan gerak peserta ekstrakurikuler sepakbola SMP Negeri 15 Malang, frekuensi terbanyak berada pada kategori sedang, yaitu 13 peserta dengan persentase $(43,3 \%)$. Hal yang menyebabkan kemampuan kondisi fisik pada unsur kelincahan peserta ekstrakurikuler sepakbola SMP Negeri 15 Malang dengan kategori "sedang" adalah Ekstrakurikuler sepakbola di SMP Negeri 15 Malang cenderung menekankan pada latihan teknik dasar permainan sepakbola dan tidak pada latihan kelincahan. Sedangkan di dalam latihan olahraga terdapat latihan kondisi fisik untuk keterampilan gerak dasar yang teratur dan sebaiknya dimulai sejak usia dini (Martínez-Vizcaino et al., 2015; Sánchez-López et al., 2019; Tappe, Glanz, Sallis, Zhou, \& Saelens, 2013; Tremblay et al., 2016). Sehingga latihan teknik dasar yang menjadi kecenderungan pada ekstrakurikuler sepakbola SMP Negeri 15 Malang seharusnya akan juga ikut terlatih secara tidak langsung ketika latihan kondisi fisik dilakukan secara terus menerus. Di samping penyebab di atas kelincahan ini dipengaruhi oleh faktor internal yang terdiri dari genetik, tipe tubuh, umur, jenis kelamin, berat badan, kelelahan, motivasi dan faktor eksternal yang terdiri dari, suhu dan kelembaban udara, arah dan kecepatan angin, ketinggian tempat, lingkungan sosial (Horicka, Hianik, \& Šimonek, 2014; Ozmen \& Aydogmus, 2016; Paul, Gabbett, \& Nassis, 2016). Sehingga dapat disimpulkan bahwa penyebab yang paling mendominasi atas kondisi fisik pada unsur kelincahan peserta ekstrakurikulum sepakbola SMP Negeri 15 Malang adalah pada proses latihan yang lebih menekankan pada teknik dasar permainan sepakbola. Hasil penelitian di atas berbeda dari penelitian yang dilakukan oleh (Saputro, 2016), kondisi fisik atlet sepakbola klub Persopi Piyungan Bantul kategori "sangat baik" sebesar 8,69\% (2 atlet), kategori "baik" sebesar 26,09\% (6 atlet), kategori "cukup" sebesar 30,43\% (7 atlet), "kurang" sebesar 26,09\% (6 atlet), "sangat kurang" sebesar 8,69\% (2 atlet). Berdasarkan nilai rata-rata, yaitu 150,11, kondisi fisik atlet sepakbola klub Persopi Piyungan Bantul masuk kategori "cukup".2.Keterampilan bermain sepakbola atletsepakbola klub Persopi Piyungan Bantulkategori "sangat baik"sebesar $0 \%$ (0 atlet), kategori "baik"sebesar 39,13\% (9 atlet), kategori "cukup"sebesar 30,43\% (7 atlet), "kurang"sebesar 21,74\% (5 atlet), "sangat kurang"sebesar 8,69\% (2 atlet). Berdasarkan nilai rata-rata, yaitu 44,84, keterampilan bermain sepakbola atlet sepakbola klub Persopi Piyungan Bantul masuk kategori “cukup”.

\section{Kondisi Fisik Kecepatan Gerak}

Pada kondisi fisik kecepatan gerak frekuensi terbanyak berada pada kategori sedang, yaitu 16 peserta dengan persentase $(53,3 \%)$, hal tersebut dikarenakan kurangnya latihan yang dilakukan oleh peserta ekstakurikuler sepakbola SMP Negeri 15 Malang dalam hal meningkatkan kecepatan gerak peserta. Hal tersebut selaras dengan apa yang dijelaskan oleh (Nurrochmah, 2016:186) bahwa kemampuan bergerak dalam waktu yang cepat dan sesingkat-singkatnya tidak dapat dilakukan dengan hasil yang maksimal tanpa adanya latihan yang dilakukan secara terus-menerus.

Bertolak dari hasil penelitian tersebut, nampak berbanding terbalik dengan dengan penelitian yang dilakukan oleh Saputra (2013), mengemukakan bahwa hasil penelitian yang dilakukan pada siswa kelas XI SMAN Mempawah Hilir terhadap keadaan fisik kemampuan gerak siswa menunjukkan hasil dengan kategori "baik" pula. 


\section{Kondisi Fisik Kelentukan Gerak}

Kemampuan kondisi fisik pada unsur kelentukan gerak, frekuensi terbanyak berada pada kategori sedang, yaitu 13 peserta dengan persentase (43,3\%). Hasil penelitian di atas juga serupa yang diteliti oleh Hilman, (2016) tentang profil kondisi fisik pemain sepakbola Perkumpulan Sepakbola Universitas Negeri Yogyakarta diperoleh hasil bahwa profil kondisi fisik pemain sepakbola Perkumpulan SepakbolaUniversitas Negeri Yogyakartaadalahsedangdengan pertimbangan frekuensi terbanyak berapa pada kategori sedang dengan 19 orang atau 76\%. Profil Kondisi Fisik PemainSepakbola Perkumpulan SepakbolaUniversitas Negeri Yogyakartayang berkategoribaik sekali 0 orang atau $0 \%$, baik 6 orang atau 24\%, sedang 19 orang atau $76 \%$, kurang 0 orang atau $0 \%$, kurang sekali 0 orang atau $0 \%$, hasil ini disebabkan karena Perkumpulan Sepakbola Universitas Negeri Yogyakarta menganggap latihan fisik sudah include dengan latihan teknik sepakbola sehingga latihan fisik secara khusus jarang dilaksanakan. Permainan sepakbola juga memerlukan permainan yang memiliki gerakan-gerakan yang dinamis serta memiliki kondisi fisik yang baik, gerakan-gerakan yang dinamis akan didapatkan ketika dilakukannya latihan sit and reach (Clemente, Lourenço Martins, \& Mendes, 2014; Grooms, Palmer, Onate, Myer, \& Grindstaff, 2013; Stubbe et al., 2015).

Pada unsur kelentukan gerak peserta ekstrakurikuler sepakbola SMP Negeri 15 Malang serupa dengan apa yang telah dipaparkan pada unsur kelincahan sebelumnya, hal ini disebabkan karena pada ekstrakurikuler sepakbola yang ada di SMP Negeri 15 Malang lebih memperhatikan teknik dasar permainan sepakbola. Meskipun sebenarnya latihan fisik tetap dilakukan akan tetapi tidak secara rutin.

\section{Kondisi Fisik Daya Ledak Otot Tungkai}

Kemampuan kondisi fisik pada unsur daya ledak otot tungkai peserta ekstrakurikuler sepakbola SMP Negeri 15 Malang, frekuensi terbanyak berada pada kategori sedang, yaitu 10 peserta dengan persentase $(33,3 \%)$. Kemampuan daya ledak otot tungkai adalah kemampuan yang sangat dibutuhkan oleh setiap cabang olahraga terlebih cabang olahraga yang menggunakan bola kaki, dalam hal ini sepakbola adalah cabang olahraga yang sangat memerlukan kemampuan daya ledak otot tungkai, sebagaimana yang dijelaskan bahwa agar pemain dapat bergerak eksplosif, pemain tersebut tidak saja dituntut memiliki kekuatan saja tetapi juga kecepatan terutama pada otot-otot kaki (Behm et al., 2017; Hartmann et al., 2015; Turner \& Stewart, 2014). Akan tetapi mengapa kemampuan yang dimiliki oleh peserta ekstrakurikuler sepakbola SMP Negeri 15 Malang hanya berada pada kategori sedang, adapun hal yang menyebabkan kemampuan tersebut tidak maksimal adalah kurangnya latihan fisik secara intens untuk memaksimalkan kemampuan tersebut, karena bukan hanya teknik permainan yang harus dimaksimalkan.

Pembahasan di atas diperkuat dengan hasil penelitian Sulasmono dan Rohman (2014:70), yang menunjukkan hasil tes lari secepatnya $35 \mathrm{~m}$ untuk power otot tungkai diketahui 5 pemain dengan nilai cukup dan sisanya 15 pemain mendapat nilai kurang serta nilai rata-rata power adalah $454 \mathrm{~nm} / \mathrm{s}$, dimana faktor yang mempengarungi hasil tersebut adalah faktor latihan,sehingga dari permbahasan tersebut dapat disimpulkan bahwa kemampuan kondisi fisik pada unsur daya tahan otot tungkai adalah intensitas latihan.

Berdasarkan hal tersebut peneliti melakukan pengumpulan data dari tes kemampuan kondisi fisik yang terdiri dari 4 butir tes yaitu tes shuttle run, teslari $50 \mathrm{~m}$, tes sit and reach dan tes standing board jump mendapatkan hasil dengan kategori "baik" sebanyak 10 peserta dengan persentase $(33,3 \%)$, kategori "sedang" sebanyak 16 peserta dengan persentase $(53,3 \%)$ dan kategori "kurang" sebanyak 3 peserta dengan persentase (10\%). Hal ini memberikan gambaran bahwa peserta ekstrakurikuler sepakbola SMP Negeri 15 Malang rata-rata memiliki kemampuan kondisi fisik pada level sedang. Dalam hal ini beberapa dari peseta ekstrakurikuler sepakbola SMP Negeri 15 Malang memiliki kemampuan dengan kategori "baik" dan "cukup" pula, sehingga dari masing-masing hasil kategori,

\section{KESIMPULAN}

Berdasarkan penelitian yang dilakukan pada peserta kegiatan ekstrakurikuler sepakbola SMP Negeri 15 Malang yang berjumlah 30 peserta diperoleh hasil tes kemampuan kondisi fisik peserta kegiatan ekstrakurikuler, maka penelitian ini dapat disimpulkan sebagai berikut. Kemampuan kondisi fisik peserta kegiatan ekstrakurikuler sepakbola SMP Negeri 15 Malang unsur kondisi fisik kelincahan gerak (shuttle run) dominan pada kategori sedang. Kemampuan kondisi fisik peserta kegiatan ekstrakurikuler sepakbola SMP Negeri 15 Malang unsur kondisi fisik kecepatan gerak lari 50 m dominan pada kategori sedang. Kemampuan 
kondisi fisik peserta kegiatan ekstrakurikuler sepakbola SMP Negeri 15 Malang unsur kondisi fisik kelentukan gerak (sit and reach) dominan pada kategori sedang. Kemampuan kondisi fisik peserta kegiatan ekstrakurikuler sepakbola SMP Negeri 15 Malang unsur kondisi fisik daya ledak otot tungkai (standing board jump) dominan pada kategori sedang.

\section{DAFTAR PUSTAKA}

Adiningtyas, W. P., Tomi, A., \& Yudasmara, D. S. (2020). Survei Pembinaan Ekstrakurikuler Bolabasket pada Peserta Didik Sekolah Menengah Atas. Sport Science and Health, 2(1), 32-38. Retrieved from http://journal2.um.ac.id/index.php/jik/article/view/11129/5120

Alesi, M., Bianco, A., Luppina, G., Palma, A., \& Pepi, A. (2016). Improving children's coordinative skills and executive functions: The effects of a football exercise program. Perceptual and Motor Skills. https://doi.org/10.1177/0031512515627527

Behm, D. G., Young, J. D., Whitten, J. H. D., Reid, J. C., Quigley, P. J., Low, J., ... Granacher, U. (2017). Effectiveness of traditional strength vs. power training on muscle strength, power and speed with youth: A systematic review and meta-analysis. Frontiers in Physiology. https://doi.org/10.3389/fphys.2017.00423

Clemente, F. M., Lourenço Martins, F. M., \& Mendes, R. S. (2014). Developing aerobic and anaerobic fitness using small-sided soccer games: Methodological proposals. Strength and Conditioning Journal. https://doi.org/10.1519/SSC.0000000000000063

Grooms, D. R., Palmer, T., Onate, J. A., Myer, G. D., \& Grindstaff, T. (2013). Soccer-specific warm-up and lower extremity injury rates in collegiate male soccer players. Journal of Athletic Training. https://doi.org/10.4085/1062-6050-48.4.08

Hartmann, H., Wirth, K., Keiner, M., Mickel, C., Sander, A., \& Szilvas, E. (2015). Short-term Periodization Models: Effects on Strength and Speed-strength Performance. Sports Medicine. https://doi.org/10.1007/s40279-015-0355-2

Hilman, M. 2016. Profil Kondisi Fisik Pemain Sepakbola Perkumpulan Sepakbola Universitas Negeri Yogyakarta. Skripsi. Yogyakarta: Universitas Negeri Yogyakarta

Horicka, P., Hianik, J., \& Šimonek, J. (2014). The relationship between speed factors and agility in sport games. Journal of Human Sport and Exercise. https://doi.org/10.4100/jhse.2014.91.06

Kurniadi, D. A. E., Wahyudi, U., \& Heynoek, F. P. (2019). Hubungan Kebiasaan Merokok terhadap Tingkat Kesegaran Jasmani Peserta Ekstrakurikuler Futsal Putra. Sport Science and Health, 1(2), 126-131. Retrieved from http://journal2.um.ac.id/index.php/jfik/article/view/10631/4793

Martínez-Vizcaino, V., Mota, J., Solera-Martínez, M., Notario-Pacheco, B., Arias-Palencia, N., García-Prieto, J. C., ... Sánchez-López, M. (2015). Rationale and methods of a randomised cross-over cluster trial to assess the effectiveness of MOVI-KIDS on preventing obesity in pre-schoolers. BMC Public Health. https://doi.org/10.1186/s12889-015-1512-0

Mora-Gonzalez, J., Esteban-Cornejo, I., Cadenas-Sanchez, C., Migueles, J. H., Molina-Garcia, P., RodriguezAyllon, M., ... Ortega, F. B. (2019). Physical Fitness, Physical Activity, and the Executive Function in Children with Overweight and Obesity. Journal of Pediatrics. https://doi.org/10.1016/j.jpeds.2018.12.028

Noperto, P. 2013. Minat Siswa Putra dalam Mengikuti Ekstrakurikuler Sepakbola SMP Negeri 5 Parindu Kabupaten Sanggau. Journal Pendidikan dan Pembelajaran, 2(9), Hal. 1-14.

Ozmen, T., \& Aydogmus, M. (2016). Effect of core strength training on dynamic balance and agility in adolescent badminton players. Journal of Bodywork and Movement Therapies. https://doi.org/10.1016/j.jbmt.2015.12.006

Paul, D. J., Gabbett, T. J., \& Nassis, G. P. (2016). Agility in Team Sports: Testing, Training and Factors Affecting Performance. Sports Medicine. https://doi.org/10.1007/s40279-015-0428-2

Priambodo, A. 2013. Tingkat Kesegaran Jasmani Atlet Putra Bolabasket Pplp Jawa Tengah Tahun 2013. 
Skripsi. Semarang: Universitas Negeri Semarang.

Reilly, J. J., Dick, S., McNeill, G., \& Tremblay, M. S. (2014). Results from Scotland's 2013 report card on physical activity for children and youth. Journal of Physical Activity and Health. https://doi.org/10.1123/jpah.2014-0183

Rhyu, H., \& Cho, S.-Y. (2014). The effect of weight loss by ketogenic diet on the body composition, performance-related physical fitness factors and cytokines of Taekwondo athletes. Journal of Exercise Rehabilitation. https://doi.org/10.12965/jer.140160

Rohman, S. 2015. Pengaruh Pelatihan Rope Jump Dengan Metode Interval Training Terhadap Kelincahan. Jurnal Kesehatan Olahraga, Volume 3. Nomor 2.Hal. 777-780.

Sánchez-López, M., Cavero-Redondo, I., Álvarez-Bueno, C., Ruiz-Hermosa, A., Pozuelo-Carrascosa, D. P., Díez-Fernández, A., ... Martínez-Vizcaíno, V. (2019). Impact of a multicomponent physical activity intervention on cognitive performance: The MOVI-KIDS study. Scandinavian Journal of Medicine and Science in Sports. https://doi.org/10.1111/sms.13383

Saputra, G., Kaswari, \& Atiq, A. (2013). Survei Keterampilan Teknik Dasar Sepakbola di Kelas XI SMAN 1 Mempawah Hilir. Jurnal Pendidikan Dan Pembelajaran, 4(8), 1-12.

Sharif, R., Chong, K. H., Zakaria, N. H., Ong, M. L., Reilly, J. J., Wong, J. E., ... Poh, B. K. (2016). Results from Malaysia's 2016 report card on physical activity for children and adolescents. Journal of Physical Activity and Health. https://doi.org/10.1123/jpah.2016-0404

Smith, M. R., Coutts, A. J., Merlini, M., Deprez, D., Lenoir, M., \& Marcora, S. M. (2016). Mental fatigue impairs soccer-specific physical and technical performance. Medicine and Science in Sports and Exercise. https://doi.org/10.1249/MSS.0000000000000762

Stubbe, J. H., Van Beijsterveldt, A. M. M. C., Van Der Knaap, S., Stege, J., Verhagen, E. A., Van Mechelen, W., \& Backx, F. J. G. (2015). Injuries in professional male soccer players in the Netherlands: A prospective cohort study. Journal of Athletic Training. https://doi.org/10.4085/1062-6050-49.3.64

Tappe, K. A., Glanz, K., Sallis, J. F., Zhou, C., \& Saelens, B. E. (2013). Children's physical activity and parents' perception of the neighborhood environment: Neighborhood impact on kids study. International Journal of Behavioral Nutrition and Physical Activity. https://doi.org/10.1186/1479-5868-10-39

Tremblay, M. S., Barnes, J. D., González, S. A., Katzmarzyk, P. T., Onywera, V. O., Reilly, J. J., ... Wong, S. H. (2016). Global matrix 2.0: Report card grades on the physical activity of children and youth comparing 38 countries. Journal of Physical Activity and Health. https://doi.org/10.1123/jpah.2016-0594

Tremblay, M. S., Gray, C. E., Akinroye, K., Harrington, D. M., Katzmarzyk, P. T., Lambert, E. V., ... Tomkinson, G. (2014). Physical activity of children: A global matrix of grades comparing 15 countries. Journal of Physical Activity and Health. https://doi.org/10.1123/jpah.2014-0177

Turner, A. N., \& Stewart, P. F. (2014). Strength and conditioning for soccer players. Strength and Conditioning Journal. https://doi.org/10.1519/SSC.0000000000000054

Utomo. 2012. Profil Kondisi Fisik Pemain futsal Porprov Karisidinen Surakarta Tahun 2012. Skripsi tidak diterbitkan. Surakarta: UNS.

Verburgh, L., Scherder, E. J. A., Van Lange, P. A. M., \& Oosterlaan, J. (2014). Executive functioning in highly talented soccer players. PLOS ONE. https://doi.org/10.1371/journal.pone.0091254

Voss, M. W., Weng, T. B., Burzynska, A. Z., Wong, C. N., Cooke, G. E., Clark, R., ... Kramer, A. F. (2016). Fitness, but not physical activity, is related to functional integrity of brain networks associated with aging. Neurolmage. https://doi.org/10.1016/j.neuroimage.2015.10.044

Wijtzes, A. I., Verloigne, M., Mouton, A., Cloes, M., De Ridder, K. A. A., Cardon, G., \& Seghers, J. (2016). Results from Belgium's 2016 report card on physical activity for children and youth. Journal of Physical Activity and Health. https://doi.org/10.1123/jpah.2016-0306 